\title{
Unusual Poisoning: Wild Berries
}

\author{
Dr. Hitender Gautam ${ }^{1}$, Dr. Priyanka ${ }^{2 *}$, Dr. Amit Sachdeva ${ }^{3}$
}

${ }^{1} J u n i o r$ Resident, Department of Paediatrics, Indira Gandhi Medical College, Shimla, Himachal Pradesh, India

${ }^{2}$ Junior Resident, ${ }^{3}$ Senior Resident, Department of Community Medicine, Indira Gandhi Medical College, Shimla, Himachal Pradesh, India

Poisoning is one of the common presentations in paediatric emergency. Common poisons encounter in paediatric age group are organophosphate, Kerosene, wild plants like Dhatura etc. But wild berry poisoning is less common. Coriaria Nepalenesis is a wild berry found in northern India and elsewhere in South Africa, china, japan and northern Africa. It had sweet fruit contain glycoside named Coriamytrin and TUTIN both act on grey Matter of cerebral cortex and cause convulsion. Children attract more towards the colourful wild berries. Some berries are toxic and cause minor GI discomfort, giddiness, seizure and even may lead to death. We, hereby report 18 cases of wild berry poisoning presenting to paediatric emergency of Indira Ganhi Medical College, Shimla. Children were between the age of 5 to 17 years. Most common presenting complaints was vomiting which was present in all the cases, 8 had altered mental status while rest 10 had generalised seizures. All children had history of consumption of wild berries accidently 2 to 4 hours before presenting to the emergency. All children had normal metabolic profile at the time of admission. Convulsions were aborted with Injection midazolam and Injection phenytoin. All were improved after 24 hours and none of them had any complication at the time of discharge. As the children had attitude to try and seek new things they are vulnerable for the exposure of poisonous wild fruit ingestion. Knowledge among children and society may decrease these incidences.

Keywords: Poisoning, paediatric, Coriaria Nepalenesis, Coriamytrin.

Copyright @ 2020: This is an open-access article distributed under the terms of the Creative Commons Attribution license which permits unrestricted use, distribution, and reproduction in any medium for non-commercial use (NonCommercial, or CC-BY-NC) provided the original author and source are credited.

\section{BACKGROUND}

During month of mid May to June, 18 children of age group 5 to 17 years were presented in emergency department of IGMC Shimla. They presented with the history of ingestion of wild berries. All the children were belonged to rural area of Distt. Shimla, Himachal Pradesh. Parents gave history of consumption of some red coloured wild berries 2 to 4 hours before admission. All had nausea, dizziness and vomiting as initial complaint. Parents also noted some red to black coloured food particles in vomitus. Ten of them had generalized convulsion, rest eight had altered mental status. Four children were actively convulsing at time of admission and rest six children were in post ictal drowsiness. There was no history of loose motions, abdominal pain, hematemesis, haematuria, chest pain or shortness of breath. Convulsion was aborted with injection midazolam and injection phenytoin was loaded at $20 \mathrm{mg} / \mathrm{kg}$. I,V fluid DNS with KCL was given to all the children admitted.
All investigations including $\mathrm{CBC}$, ESR, Urine analysis, Blood sugar, KFT and Electrolytes were within normal range. Chest X-ray, ECG and Ultrasound examination of the abdomen were also normal. Repeat investigations were done after 24 hour of admission which was also found normal.

Injection phenytoin was gradually tapered off over next 2 days. No seizure episode was occurred after admission. All children were conscious and oriented within 24 hours of admission. All the children were discharged after 3-4 days. Follow up of the patients had been done after 1 week, all children were asymptomatic at that time.

Although, the nature of the poison could not be established and also the toxin could not be identified from the patient. Plant and its fruit which was shown by the parents, identified as Coriaria Nepalenes (Fig). This plant have a toxin called "TUTIN" a potent neurotoxin causing convulsions which has no known antidote and requires symptomatic treatment if the presentation is early but otherwise fatal if treatment is delayed. 


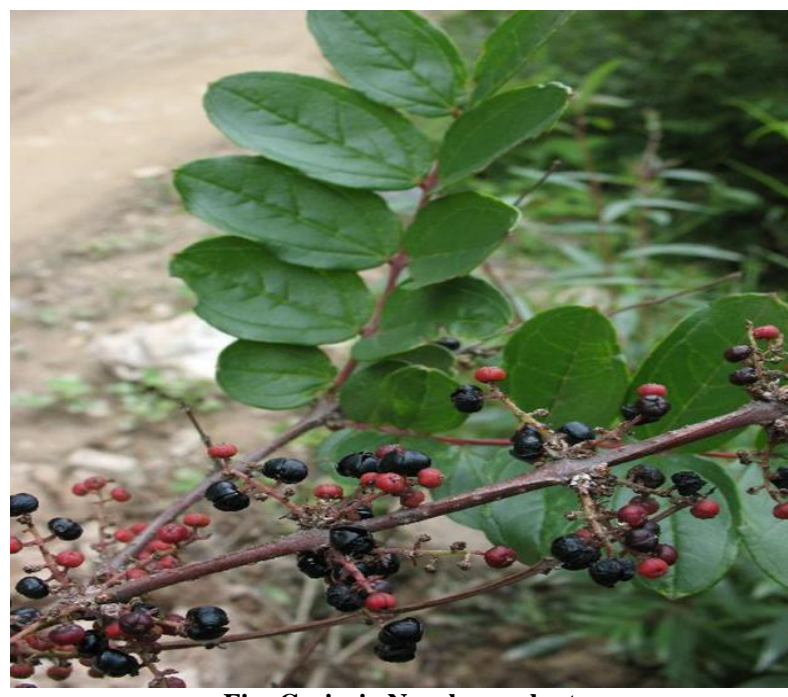

Fig: Coriaria Nepalenes plant

\section{DISCUSSION}

Cases of accidental poisoning are not uncommon among the children in all over the world [1]. The incidence of accidental poisoning varies widely ranging from $0.33 \%$ as reported by Satpathy et al., [2] and 5 to $7.64 \%$ by Buhariwalla et al., [3] Accidental ingestion of plant poisons like dhatura, caster seeds has been well known in india [4]. In children the major factors involved in accidental poisoning are the inexperienced child, a toxic agent, an unsafe environment, ignorance of the parents and impulsive attitude of the child to try and seek new things. Although the samples were not sent for chemical analysis to find out the toxin present in it but the plant (leaves and fruit) was brought to emergency by parents identified by the parents was a bushy plant Coriaria Napalensis belong of the Family Coriariaceae, an exotic angiospermus grown as an ornamental in Himachal Pradesh, Kashmir \& elsewhere in South Europe, South America, China, Japan, North Africa \& New Zealand. The earliest reference with respect to the description of this plant has been recorded in 1773 in New Zealand when two sheep were found to be dead after the consumption of this plant [5]. Since then the plant has been extensively studied in New Zealand, China \& Nepal for its varied properties of poisoning. The earliest symptoms of poisoning recorded in humans were vomiting, giddiness, delirium, stupor, coma, convulsions \& death. Coriaria nepalenesis was most common in sub Himalayan region, many other species was found worldwide like $\mathrm{C}$ thymifolia, $\mathrm{C}$ ruscifolia. \& C.myrtifolia [6,7]. Various poisons were isolated from these plants out of which TUTIN was extensively studied. It is a potent neurotoxin leads to convulsion and even fatal at high doses. TUTIN is poisonous in small doses $(0.01 \mathrm{gm}) \&$ causes convulsions \& is fatal in about 5 hours if untreated [8, 9]. Riban also isolated a glycoside named Coriamyrtin from the plantit is also a potent neurotoxin act on grey matter and lead to convulsion [10].

\section{RECOMMENDATION}

IEC activity should be done to educate parents and children not to consume these kinds of wild berries. The use of these plants as ornamental plant should also be discouraged.

\section{REFERENCES}

1. Sitaram S, Sharma U, Saxena S. Accidental Poisoning in Children. Indian Pediatrics, 1985; 22: 757-760.

2. Satpathy R, Das BB. Accidental Poisoning in Childhood. Journal Indian Med Assoc, 1979; 73: 190-192

3. Buhariwalla RJ, Sanjanwalla. Poisoning in Children. A study of 303 cases. Indian Pediatrics, 1969; 6: 141-145.

4. Buch NA, Kaiser A, Sethi AS. Poisoning in Children. Indian Pediatrics, 1991; 28:521-524

5. Andrew Kippis DD. Life \& voyages of Captain James Cook by; FRS. George Newnes (Limited); 1904: 179.

6. Laing RM, Blackwell EW. Plants of New Zealand by, New Zealand, 1906:228.

7. Featon EH. Art Album of New Zealand Flora by Mr \& Mrs. London, 1889; (1): 104.

8. Easterfield TH, Aston BC. Tutu Part 1 by. Wellington 1900. Available from: www.worldcat.com (last accessed on 07 June 2020.)

9. Cheeseman TF. Manual of New Zealand flora by FLS, FZS. Wellington 1906. 105. Available from: www.biodiversitylibrary.org (last accessed on 07 June 2020).

10. Riban MJ. Sur le Coriamyrtin et ses Derives by. Comptes Rendus. Paris, 1866:746. 